\title{
Portföy Yatırımları İle Ekonomik Büyüme İlişkisi: 23 OECD Ülkesi İçin Panel Veri Analizi
}

\author{
Portfolio Investments And Economic Growth Relationship: Panel Data Analysis For \\ The 23 OECD Countries
}

\author{
İbrahim Halil SUGÖZÜ* \\ Sema YAŞAR**
}

\begin{abstract}
$\ddot{O} Z$
Portföy yatırımları, ödemeler bilançosu dengesinde sermaye hesabı altında bulunan doğrudan yabancı sermaye yatırımları ve kredilerle birlikte üçüncü bir kalem olan ve içerisinde tahvilleri ve hisse senetlerini ihtiva eden dolaylı yabancı sermaye yatırımlarıdır. Diğer kalem olan doğrudan yabancı sermaye yatırımları ülkeye dişarıdan yapılan reel yatırımları ifade ederken portföy yatırımları, ülkenin klymetli kağıtlarına yapılan finansal yatırımlar ifade etmektedir. Bu kiymetli kağıtlar karşıllğında ülkeye sıcak para girişi yaşanmakta, vadesinin gelmesi veya diğer nedenlerle bu para, faizi veya karı ile birlikte ülke dışına çıkmaktadır. İstihdam artışı gerçekleştirmeden yüksek büyüme rakamlarına ulaşan gelişmekte olan ülkelerde bu büyümenin kaynağının dışarıdan ülkeye giren finansal varllklar olduğu ve bunun sürdürülebilirliğinin olmadığı kanaati hakimdir. Yapılan bu çalışmada portföy yatırımlarının büyümeye etkisi, 2001-2018 dönemi için 23 OECD ülkesi üzerine yapılan panel veri analizi ile test edilmiștir. Analiz sonucunda Driscoll-Kraay tahmincisi ile yapılan regresyon analizi sonucunda portföy yatırımlarındaki artışın ekonomik büyümeyi kisa dönemde pozitif yönde etkilediği ancak değişkenlerin eşbütünleşik olmadıkları yani uzun dönem ilişskilerinin olmadı̆ğ tespit edilmiştir. Analiz sonucu portföy yatırımlarının kısa dönemde büyümeyi pozitif etkilediği ancak uzun dönemde sürdürülebilir olmadı̆̆ı kanaatini doğrulamaktadır.
\end{abstract}

ANAHTAR KELIMELER

Portföy Yatırımları, Ekonomik Büyüme, Panel Veri Analizi

\begin{abstract}
Portfolio investments which include bonds and stocks, are indirect foreign capital investments which is a third item together with direct foreign capital investments and loans, under the capital account in the balance of payments balance. The other item, direct foreign capital investments, refers to real foreign investments in the country, while portfolio investments represent the financial investments made in the country's securities. In return for these securities, hot money is entering the country and due to the maturity or other reasons, this money goes out of the country with interest or profit. In developing countries that have reached high growth figures without an increase in employment, it is considered that the source of this growth is the financial assets entering the country from outside and this is not sustainable. In this study, the effect of portfolio investments on growth was tested with panel data analysis on 23 OECD countries for the period 2001-2018. As a result of the analysis, the regression analysis made with Driscoll-Kraay estimator showed that the increase in portfolio investments positively affected economic growth in the short term, but the variables were not cointegrated, ie long-term relationships. The analysis confirms that portfolio investments positively affect growth in the short run but are not sustainable in the long run.
\end{abstract}

\section{KEYWORDS}

Portfolio Investments, Economic Growth, Panel Data Analysis

\begin{tabular}{|c|c|c|}
\hline \multicolumn{2}{|c|}{ Makale Geliş Tarihi / Submission Date } & \multicolumn{1}{c|}{$\begin{array}{c}\text { Makale Kabul Tarihi / Date of Acceptance } \\
30.03 .2020\end{array}$} \\
\hline \multirow{3}{*}{ Atıf } & $\begin{array}{l}\text { Sugözü, İ.H. ve Yaşar, S. (2020). Portföy Yatırımları İle Ekonomik Büyüme İlişkisi: 23 OECD Ülkesi İçin Panel Veri } \\
\text { Analizi. Selçuk Üniversitesi Sosyal Bilimler Meslek Yüksekokulu Dergisi, 23 (1), 198-207. }\end{array}$ \\
\hline
\end{tabular}

\footnotetext{
* Prof. Dr., Şrnak Üniversitesi İktisadi ve İdari Bilimler Fakültesi, İktisat Bölümü, ihsugozu@sirnak.edu.tr, ORCID: 0000-0002-1861-3118

** Dr. Öğr. Üyesi, Şırnak Üniversitesi İktisadi ve İdari Bilimler Fakültesi, İktisat Bölümü, semayasar@sirnak.edu.tr , ORCID: 0000-0002-7056-9265
} 


\section{GİRIŞ}

1980'li yıllarda uluslararası finansal hareketlerin serbestleşmesi konusunda önemli adımlar atılması dolayısıyla bu yıllar ve özellikle 1990'lar, ödemeler bilançosunda bulunan sermaye hesabının niteliği ve niceliğindeki gelişmeler için önemli yıllardır. Bununla birlikte merkez bankalarının da içerisine dahil edildiği bankacılık sektöründe de önemli gelişmeler yaşanmıştır. Aslında reel sektörün ihtiyaçlarına cevap vermekle mükellef olan ve serbestleşme ile de bu amaca daha iyi hizmet etmesi hedeflenen finans sektörü bir bakıma spekülatif hareketleri merkeze alarak kendi içerisinde de döngüye sahip başlı başına bir yapıya bürünmüştür. Böylece finans sektörü, Türkiye gibi sanayi ve teknolojide uluslararası gelişmelere ayak uyduramadığından dolayı reel sektörü yeterli düzeyde büyüyememiş ülkelerin en büyük sektörü haline gelmiştir. Sermaye hareketlerinde serbestlik ve yabancı yatırımların önündeki engellerin kalkmasıyla bu sektörün önemli bir kısmı da yabancı yatırımcıların ortaklığına dönüşmüştür. Benzer gelişmeler daha ileri boyutta borsada da yaşanmış ve yabancı yatırımcılar yerli yatırımcılardan daha büyük paya sahip olmuşlardır.

Finansal serbestleşmenin doğrudan etkileri portföy yatırımlarında meydana gelen değişim ve uluslararası kredi hareketleri yoluyla gerçekleşmektedir. Finansal serbestleşmenin doğrudan ve dolaylı etkileri faiz, döviz kurları, emisyon, enflasyon ve borsa göstergeleri üzerinden yansımıştır. Bu göstergeler ise yatırım, üretim, istihdam ve diş ticaret gibi reel değişkenleri etkilemektedir. Nihayetinde bu etkiler milli geliri meydana getiren ücret, faiz, kar ve rant gelirleri arasındaki dağılımı belirleyen fonksiyonel gelir dağılımını belirlemektedir (Yılmaz, 2011: 84). Finansal serbestleşme, göstergeler ve etkilediği değişkenler açısından faiz lehine dağılımın yeniden gerçekleştiği bir sonucu ortaya çıkarmaktadır.

Portföy yatırımları, ödemeler bilançosunda sermaye hesabının altındaki reel yabancı yatırımları temsil eden doğrudan yabancı sermaye yatırımlarından sonra finansal yatırımları (plasman) temsil eden dolaylı yatırımları göstermektedir. Tahvil ve hisse senedi gibi iki önemli araca ve diğer finansal varlıklara sahip olan portföy yatırımları için özellikle finansal istikrarsızlık dönemlerinde kısa vadeli olmak üzere yoğunlaşması dolayısıyla sıcak para ifadesi de kullanılmaktadır. Portföy yatırımlarının ilk aracı olan tahvil, yatırımcısına faiz getirisi sağlayan borçlanma senetleri iken, hisse senedi, kar getirisi sağlayan borsa firmalarının ortaklık senetleridir. Uluslararası sermaye akımlarının yüksek faiz ve yüksek kar getirisi sağlayan ülkelere yöneldiği düşünüldüğünde sermaye ihtiyacı olan ülkelerin ilk olarak yeterli düzeyde yüksek faiz oranlarına sahip olmaları ve ikinci olarak uluslararası piyasalarda güven sağlamaları zorunlu hale gelmektedir.

Başta portföy yatırımları olmak üzere yabancı finansal sermaye girişlerine bağımlı hale gelen ülkeler, yabancı yatırımcıların güvenini sağlayacak politikaları temel amaç haline getirerek bu politikaları ister istemez uygulamak ya da sürdürmek zorunda kalacaklardır. Buna Portföy yatırımlarının ülkenin ekonomi politikaları üzerindeki kısıtlayıcı etkisi denilmektedir. Portföy yatırımlarının en önemli kısıtlayıcı etkisi, para politikaları üzerindeki etkisidir. Yabancı yatırımcılar ülke riskini ve kur riskini dikkate alacakları için genelde yatırım yapacakları ülkelerde daraltıcı para politikalarının uygulanmasını tercih edeceklerdir (Esen, 1998: 62). Portföy yatırımlarını çekmek isteyen ülkelerin ekonomi politika yapıcıları daraltıcı para politikası uygulamak zorunda kalacaklardır. Başka bir sorun ise portföy yatırımlarının finansal yatırım olması nedeniyle dönüş hızının yüksek olmasıdır. Ülkeden sermaye çıkışının hızlı bir şekilde gerçekleşmesi ekonomi üzerinde tahripkar bir etki meydana getirecektir. Böylece finans ekonomisini benimseyip uygulayan ülkeler diş şoklara daha duyarlı hale geleceklerdir (Sugözü ve Çetinkaya, 2010: 245). Bunun en göz önündeki sonucu ise son dönemde yoğunlaşan küresel finansal krizlerdir.

Uluslararası sermaye piyasalarındaki bu yeni eğilim, sermaye akımlarının nedenleri ve gelişmekte olan ülkelerin (GOÜ) ekonomilerinin performanslarına etkileri konusunda bir dizi sorunu ortaya çıkarmıştır. Türkiye'de (1994), Meksika'da (1994) ve Doğu Asya ülkelerinde (1997) yaşanan finansal krizler çoğunlukla dikkatleri GOÜ'lere yatırım yapan yatırımcıların riskleri üzerinde yoğunlaştırırken genel olarak sermaye akımlarının özel olarak da portföy yatırımlarının GOÜ ekonomilerine olan gerçek risklerine çok az dikkat çekilmiştir (Esen, 1998: 59). Kısa vadede reel sektör yatırımları için tasarruf ihtiyacını karşılayan uluslararası sermaye hareketlerinin, yüksek cari açığa sahip ülkelerde bu açığın kapatılması için kullanılması neticesinde faiz giderleri ile birlikte ülkeden ayrılması, uzun vadede sürdürülebilir bir kaynak olma özelliğini ortadan kaldırıp, cari açığı daha da artıran borçlanma özelliğini baskın kılmaktadır. Bundan dolayı yapılmış olan çalışmalarda özellikle gelişmekte olan ülkelerde kısa dönemde pozitif etkiye sahip olan doğrudan yatırımların etkisinin uzun vadede tersine döndüğ̈ sonuçları ile karşılaşılmaktadır.

Yapılan bu çalışma bu anlamda oldukça önem taşımakta ve 2000 yılı sonrasındaki durum ile ilgili analiz sonuçlarını ortaya koymaktadır. Çalışma sırasıyla, giriş, kavram ve tanımlarla ilgili teorik bilgiler, literatür taraması ve ekonometrik analiz bölümlerinden oluşmaktadır. Çalışmada G8 ülkeleri dışında kalan 23 OECD üyesi ülkeye 2001-2018 döneminde yapılan yabancı portföy yatırımlarının bu ülkelerin gayrisafi yurtiçi 
hasılalarına kısa ve uzun dönemde etkisi incelenmiştir. Gayrisafi Sermaye yatırımlarının da açıklayıcı değişkenlere eklendiği analiz için panel veri analizi kullanılmıştır. Ampirik bulgular yukarıda belirtilen kaygıyı doğrulamakta ve kısa dönemde ekonomik büyümeye olumlu katkı sunan portföy yatırımlarının uzun dönemde büyüme ile birlikte hareket etmediği sonucunu ortaya koymaktadır.

\section{LITERATÜR TARAMASI}

Bekaert ve Harvey (1998), portföy yatırımları ve ekonomik büyüme arasındaki ilişkiyi incelemek amacıyla yapmış oldukları çalışmada ABD'den 17 tane gelişmekte olan ülkeye giren portföy yatırımlarını incelemişlerdir. Çalışmalarının sonucunda ise ülkelere giren tahvil ve hisse senedinin yani portföy yatırımlarının söz konusu gelişmekte olan ülkelerdeki ekonomik büyümeyi pozitif yönde etkilediğini tespit etmişlerdir. Reisen ve Soto (2001) da söz konusu değişkenler arasındaki ilişkiyi 44 tane gelişmekte olan ülke için 1986-1997 dönemi verileri ile Genelleştirilmiş Momentler yöntemini kullanarak incelemişler ve aynı sonuca ulaşmışlardır. Mc Lean ve Shrestha (2002) ise Asya, Afrika ve Latin Amerika'da yer alan 40 tane gelişmekte olan ülke için 1976-1994 dönemi, Karaca ve Abasız (2008), düşük gelirli ülkeleri ele aldığı çalışmalarında 25 tane gelişmekte olan ülke için 1980-2005 dönemi ve Vergil ve Karaca (2010), Türkiye'nin de aralarında bulunduğu 25 gelişmekte olan ülke için 1980-2005 dönemi verilerini kullanarak panel veri analizi yapmışlardır. Gelişmekte olan ülkelerin incelendiği bu çalışmaların neticesinde de portföy yatırımlarının ekonomik büyümeyi pozitif yönde etkilediği sonucu elde edilmiştir. Demir (2007) ise portföy yatırımları ve doğrudan yabancı yatırımlarından oluşan uluslararası sermaye hareketlerinin Türkiye'de ekonomik büyüme üzerindeki etkisini incelemek amacıyla 1996-2005 dönemi aylık verileri ile zaman serisi analizi yapmıştır. Diğer çalışmaların sonuçlarına benzer şekilde portföy yatırımlarının ekonomik büyümeyi pozitif yönde etkilediğini tespit etmiştir.

Durham (2004), 80 ülke için 1979-1998 dönemi verileri ile regresyon analizi ve sınır testi yapmıştır. Albulescu (2015) ise, çalışmasında Bulgaristan, Hırvatistan, Kıbrıs, Çek Cumhuriyeti, Estonya, Macaristan, Letonya, Litvanya, Malta, Polonya, Romanya, Slovakya ve son olarak da Slovenya'nın bulunduğu 13 orta ve doğu Avrupa ülkesi için 2005-2012 dönemi verileri ile GMM yaklaşımını kullanarak uygulamış olduğu panel veri analizi neticesinde önceki çalışmalarla benzer sonucu elde etmişlerdir.

Vita ve Kyaw (2009), 126 tane gelişmekte olan ülke için ekonomik büyüme ile portföy yatırımları arasındaki ilişkiyi incelemek amacıyla 1985-2002 dönemi verileri ile panel veri analizi yapmışlardır. İnceledikleri ülkeleri düşük gelirli, orta gelirli ve yüksek gelirli olmak üzere üç gruba ayırarak GMM tahmin yöntemini uygulamışlardır. Analizlerinin neticesinde üst orta gelirli ve gelişmekte olan ülkelerde ekonomik büyüme ve portföy yatırımları arasında pozitif bir etki olduğunu tespit etmişlerdir. Singh ve Weisse (1998), gelişmekte olan ekonomilerde portföy yatırımlarının ekonomik büyüme ve gelişme üzerindeki etkisini mikro ve makroekonomik açıdan incelemişlerdir. Portföy yatırımlarının gelişmekte olan ülkelerin ekonomik büyümeleri üzerinde pozitif yönlü bir etkisinin olabilmesinin bu ülkelerin bankacılık sistemini geliştirmelerine ve sermaye hareketlerinin bileşenleri ile boyutunu belirlemelerine bağlı olduğu yönünde bir sonuca ulaşmışlardır.

Aizenman vd. (2011), küresel kriz öncesi ve sonrası olmak üzere 1990-2010 dönemi 100 gelişmekte olan ülke için sermaye girişleri ve ekonomik büyüme arasındaki ilişkiyi incelemişlerdir. Portföy yatırımlarının ekonomik büyüme üzerindeki etkisinin oldukça küçük ve istikrarsız olduğu sonucuna ulaşmışlardır. Kuzucu (2018), gelişmekte olan ülkelere yapılan sermaye yatırımlarının ekonomik büyüme üzerindeki etkisini incelemek amacıyla 52 gelişmekte olan ülke için panel veri analizi yapmıştır. 2005-2015 periyodundaki veriler ile yapmış olduğu çalışmasının sonucunda ise gelişmekte olan ülkelerde portföy yatırımlarının ekonomik büyüme üzerindeki etkisinin belirsiz olduğunu tespit etmiştir. Portföy yatırımlarının tasarruf açığı olan ülkelerde yatırımlar için finansman kaynağı olması sebebiyle olumlu, ancak kırılganlığı artırdığı ve dolayısıyla finansal krizlere neden olduğu için de olumsuz etkisi olabileceğini belirtmiştir.

Benli (2019), 2016 yılı için 23 gelişmiş ülke ile 33 gelişmekte olan ülkenin kesitler arası verilerini kullanarak portföy yatırımları ile ekonomik büyüme arasındaki ilişkiyi incelemiştir. $\mathrm{Bu}$ amaçla portföy yatırımı, ekonomik büyüme ve diğer ekonomik, sosyal ve kurumsal değişkenler arasında tümevarımlı nedensel çıkarım tabloları oluşturmuştur. Yönlendirilmiş döngüsüz graf şablonları ile gelişmiş ekonomilerde ekonomik büyümenin dolaylı yönden portföy yatırımlarının bir sonucu olduğunu tespit etmiş, gelişmekte olan ekonomilerde ise portföy yatırımlarının ekonomik büyümeyi takip ettiği sonucuna ulaşmıştır.

Soto (2000), 44 gelişmekte olan ülkenin 1986-1997 dönemi sermaye girişleri ve ekonomik büyümeleri arasındaki ilişkiyi dinamik panel veri analizi ile incelemiştir. Portföy yatırımlarını hisse senetleri ve tahviller bazında ayrı ayrı ele almıştır. Hisse senetleri ile ekonomik büyüme arasında pozitif yönlü bir ilişki tespit etmesine rağmen tahviller ile ekonomik büyüme arasında ise anlamlı bir ilişki olmadığı yönünde bir sonuç 
elde etmiştir. Kula (2003) ise, çalışmasında Türkiye için 1980-2000 dönemi portföy yatırımları ile ekonomik büyüme arasındaki ilişkiyi korelasyon analizi ile test etmiştir. Çalışmasının sonucunda ise portföy yatırımları ile ekonomik büyüme arasında negatif yönlü korelasyon tespit etmiştir.

\section{EKONOMETRIKK YÖNTEM VE VERİ SETİ}

Seçilmiş 23 OECD ülkesinde portföy yatırımları ve ekonomik büyüme arasındaki ilişkinin incelenmiş olduğu bu çalışmada portföy yatırımları, sabit sermaye yatııımları ve Gayrisafi Yurtiçi Hasıla (GSYH) verileri kullanılarak panel veri analiz yöntemi uygulanmıştır. Modelde ele alınan değişkenler ve bu değişkenlere ait bilgiler Tablo 1'de verilmektedir.

Tablo 1. Modelde Kullanılan Değişkenler

\begin{tabular}{|l|l|l|l|}
\hline Değişkenler & Açıklama & Dönem, Cinsi, Değer & Kaynak \\
\hline InGSYH & $\begin{array}{l}\text { Gayri Safi Yurtiçi Hasıla } \\
\text { GSYH) }\end{array}$ & $\begin{array}{l}\text { Y1llı, ABD Doları, } \\
\text { Logaritma }\end{array}$ & $\begin{array}{l}\text { World Bank- World } \\
\text { Development Indicators }\end{array}$ \\
\hline InPOY & Portföy Yatırımları & $\begin{array}{l}\text { Y1llı, ABD Doları, } \\
\text { Logaritma }\end{array}$ & IMF Data Warehouse \\
\hline InGSSY & $\begin{array}{l}\text { Gayrisafi Sabit Sermaye } \\
\text { Oluşumu }\end{array}$ & $\begin{array}{l}\text { Yllık, ABD Doları, } \\
\text { Logaritma }\end{array}$ & $\begin{array}{l}\text { World Bank- World } \\
\text { Development Indicators }\end{array}$ \\
\hline
\end{tabular}

Portföy yatırımları ile ekonomik büyüme arasındaki ilişki, özellikle G8 ülkeleri dışında kalan 23 OECD ülkesinin 2001-2018 dönemi y1llık verileri ile incelenmiştir. Literatür taramasında da görüldüğü gibi portföy yatırımları açısından gelişmiş ülkeler ile gelişmekte olan ülkelerin farklı özelliklere sahip olması ve bu yüzden birbirlerinden farklı sonuçlar vermesinden dolayı bu çalışmada G8 ülkeleri dışarıda bırakılarak gelişmişlik açısından birbirine daha yakın 23 OECD ülkesi verileri analizde kullanılmıştır.

\section{EKONOMETRÍK METODOLOJİ VE BULGULAR}

Panel veri analizinde kullanılacak olan verilerin yatay kesit bağımlılı̆̆ içerip içermediği yapılacak olan testlerin belirlenmesinde oldukça önemli olduğundan öncelikle verilerin yatay kesit bağımlılıkları test edilmiştir. Ardından modelin sabit etkili mi ya da rassal etkili mi olduğunu belirlemek amaciyla Hausman testi yapılmıştır. Sonrasında sırasıyla otokorelasyon, değişen varyans, yatay kesit bağımlılı̆̆ını dikkate alan ikinci nesil birim kök testi olan CADF birim kök testleri uygulanmıştır. Birim kök testi neticesinde eşbütünleşme analizi yapılmıştır. Sabit etkiler panel veri yöntemi ile tahmin edilen modelde, yatay kesit bağımlılığını dikkate alan, otokorelasyon ve değişen varyansa karşı dirençli tahminciler veren Driscoll-Kraay testi uygulanmıştır.

Panel veri analizlerinde, bir ülkede yaşanan ekonomik şokun ele alınan diğer ülkeleri de etkileyip etkilemediğini tespit edebilmek amacıyla yatay kesit bağımlılığının test edilmesi gerekmektedir. Yatay kesit bağımlılığının tespit edilmesinde birçok test kullanılmaktadır. Pesaran (2004) $C D$ testi $T>N$ ve $T<N$ durumunda kullanılabilmektedir. Pesaran (2004) tarafından geliştirilen yatay kesit bağımlılığı testi aşağıdaki gibidir (Pesaran, 2008: 109):

$$
C D_{L M 3}=\sqrt{\frac{2 T}{N(N-1)}}\left(\sum_{i=1}^{N-1} \sum_{j=i+1}^{N} \hat{p}_{i j}\right)
$$

Pesaran (2004) tarafından geliştirilen yatay kesit bağımlılı̆̆ testinin hipotezleri ise aşağıdaki gibidir:

$H_{0}=$ Yatay kesit bağımlılı̆ 1 yoktur.

$H_{1}=$ Yatay kesit bağımlılı̆ 1 vardır.

Modelde kullanılan değişkenlere ait yatay kesit bağımlılığı testi sonuçları Tablo 2'de yer almaktadır.

Tablo 2. Değişkenlere Ait Yatay Kesit Bağımııı̆ı̆ı Testi Sonuçları

\begin{tabular}{|l|c|c|c|c|}
\hline Değişkenler & lnGSYH & InPOY & lnGSSY & Model \\
\hline Pesaran CD & 61.83259 & 53.44384 & 50.59878 & 18.15838 \\
\hline Olasılık Değeri & 0.0000 & 0.0000 & 0.0000 & 0.0000 \\
\hline Karar & Red & Red & Red & Red \\
\hline
\end{tabular}

Tablo 2'de yer alan sonuçlar incelendiğinde değişkenlere ait $H_{0}$ hipotezinin reddedildiği yani yatay kesit bağımlılığının olduğu görülmektedir. Tablo 2'de modelin CD Test istatistiği de verilmektedir. 
Tablo 3. Modele Ait Yatay Kesit Bağımlılığı Testi Sonuçları

\begin{tabular}{|l|c|c|c|}
\hline Test & Test İstatistiği & Probabilite Değeri & Karar \\
\hline Pesaran Scaled LM & 36.86450 & 0.0000 & Red \\
\hline
\end{tabular}

Tablo 3'te ise modele ait Peseran Scaled LM yatay kesit bağımlılığı testi sonucu bulunmaktadır. Sonuçlar incelendiğinde değişkenlerde olduğu gibi modelde de yatay kesit bağımlılığının bulunduğu görülmektedir. Bu sonuçlar paneli oluşturan ülkeler arasında yatay kesit bağımlılığı olduğunu göstermektedir.

Değişkenler arasında yatay kesit bağımlılığının tespit edilmesi durumunda yatay kesit bağımlılığını dikkate alan ikinci nesil birim kök testleri geliştirilmiştir. Bu çalışmada birim kök analizi ikinci nesil birim kök testlerinden Pesaran (2006) tarafindan geliştirilen CADF (Cross-sectionally Augmented Dickey-Fuller) birim kök testi ile gerçekleştirilmiştir. CADF istatistiği hem $\mathrm{N}>\mathrm{T}$ hem de $\mathrm{T}>\mathrm{N}$ olması durumunda geçerlidir. CADF test istatistiği aşağıdaki gibidir:

$$
\begin{aligned}
& \quad y_{i t}=\left(1-\varphi_{i}\right) \mu_{i}+\varphi_{i} y_{i, t-1}+u_{i t} \\
& i=1, \ldots, N \text { ve } t=1, \ldots ., T \\
& u_{i t}=y_{i} f_{t}+\varepsilon_{i t}
\end{aligned}
$$

Yukarıdaki denklemde yer alan $f_{t}$ gözlemlenemeyen ortak etki iken, $\varepsilon_{i t}$ ise bireysel hatayı ifade etmektedir. Birim kök hipotezleri ise aşağıdaki gibi oluşturulmaktadır (Pesaran, 2007: 268):

$\Delta y_{i t}=\alpha_{i}+\beta_{i} y_{i, t-1}+y_{i} f_{t}+\varepsilon_{i t}$

$H_{0}: \beta_{i}=0$ Bütün i'ler için (Durağan değildir)

$H_{1}: \beta_{i}<0, i=1,2, \ldots \ldots N_{1}, \beta_{i}=0, i=N_{1}+1, N_{1}+2, \ldots \ldots N \quad$ (Durağandır)

Her bir yatay kesiti ifade eden ülkelerin birim köklerinin ortalamaları alınarak panel için genel bir birim kök istatistiği olan CIPS (Cross-Sectionally Augmented IPS) elde edilmektedir. Bu durumda CIPS istatistiği ise aşağıdaki gibidir (Pesaran, 2007: 267):

$$
\text { CIPS }=N^{-1} \sum_{i=1}^{N} C A D F_{i}
$$

\begin{tabular}{|c|c|c|c|c|}
\hline \multirow{2}{*}{ Değişken } & \multicolumn{2}{|c|}{ Seviye } & \multicolumn{2}{|r|}{ 1.Fark } \\
\hline & Gecikme & CIPS istatistiği & Gecikme & CIPS istatistiği \\
\hline InGSYH & 2 & -2.070 & 2 & $-2.527 *$ \\
\hline $\ln P O Y$ & 2 & -1.795 & 2 & $-3.692 *$ \\
\hline lnGSSY & 1 & -2.087 & 1 & $-2.624 *$ \\
\hline \multirow{3}{*}{$\begin{array}{l}\text { Sabit ve } \\
\text { Trendsiz } \\
(\mathrm{N}: 23, \mathrm{~T}: 18)\end{array}$} & $\% 1$ & -2.40 & & \\
\hline & $\% 5$ & -2.21 & & \\
\hline & $\% 10$ & -2.10 & & \\
\hline
\end{tabular}

Modele ait CADF birim kök testi sonuçları Tablo 4'te verilmektedir.

Tablo 4. Cross-sectionally Augmented Dickey-Fuller (CADF) Birim Kök Testi Sonuçları

Tablo 4 incelendiğinde, modelde yer alan tüm değişkenlerin seviyede birim köke sahip oldukları ancak birinci farklarında ise durağan hale geldikleri görülmektedir.

Panel veri analizi çerçevesinde sabit etkiler modeli veya rassal etkiler modeli kullanılmaktadır. Her iki modelden hangisinin daha etkin olduğunu tespit edebilmek amacıyla Hausman Testi uygulanmaktadır. Bu test 
k serbestlik dereceli ki-kare dağılımına bağlıdır ve birimlerin neden olduğu etkilerin modeldeki bağımsız değişkenler ile korelasyonlu olup olmadıklarını incelemektedir (Baltagi, 2001: 20).

Hausman testinde sabit etkiler modelinden elde edilmiş olan katsayılar ile rassal etkiler modelinden elde edilmiş olan katsayıların aynı olduğunu ifade eden $H_{0}$ hipotezinin reddedilmesi, sabit etkiler modelinin geçerli olduğu anlamını taşımaktadır.

Hausman Testi için oluşturulan hipotezler aşağıdaki gibidir:

$H_{0}$ : Katsayılar arasındaki fark sistematik değildir (Rassal Etkiler Modeli).

$H_{1}$ : Katsayılar arasındaki fark sistematiktir (Sabit Etkiler Modeli).

Modele ilişkin Hausman testi sonuçları Tablo 5'te yer almaktadır.

Tablo 5. Hausman Testi Sonucu

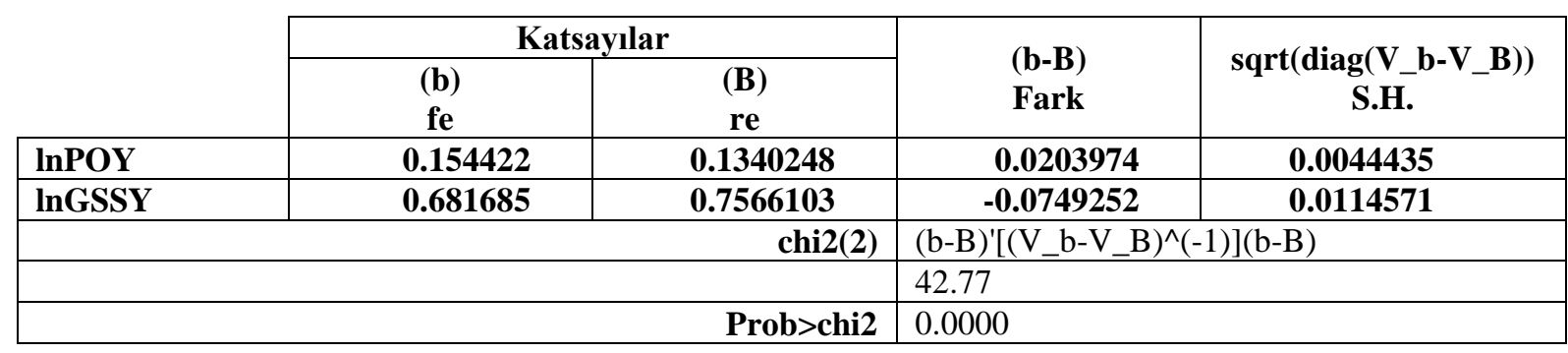

Hausman testine ait sonuçlar değerlendirildiğinde $H_{0}$ hipotezinin reddedildiği, katsayılar arasındaki farkın sistematik olduğunu ileri süren sabit etkiler modelinin geçerli olduğunu ifade eden $H_{1}$ hipotezinin kabul edildiği görülmektedir.

Hausman testi neticesinde sabit etkiler modelinin geçerli olduğunun tespit edilmesiyle modelin ekonometrik açıdan yapılan varsayımlara uygunluğunu belirlemek amacıyla otokorelasyon testi yapılmıştır. $\mathrm{Bu}$ amaçla Bhargava, Franzini ile Narendranathan (1982) tarafından geliştirilen Durbin-Watson testi ile Baltagi ve Wu (1999) tarafindan geliştirilen LBI testi yapılmıştır. Söz konusu testlerde olasılık değeri hesaplanmamakta, test istatistik sonuçlarının 2'den küçük olması durumunda otokorelasyon olduğu sonucu elde edilmektedir.Modele ait otokorelasyon testi sonuçları Tablo 6'da yer almaktadır.

Tablo 6. Otokorelasyon Testi Sonucu

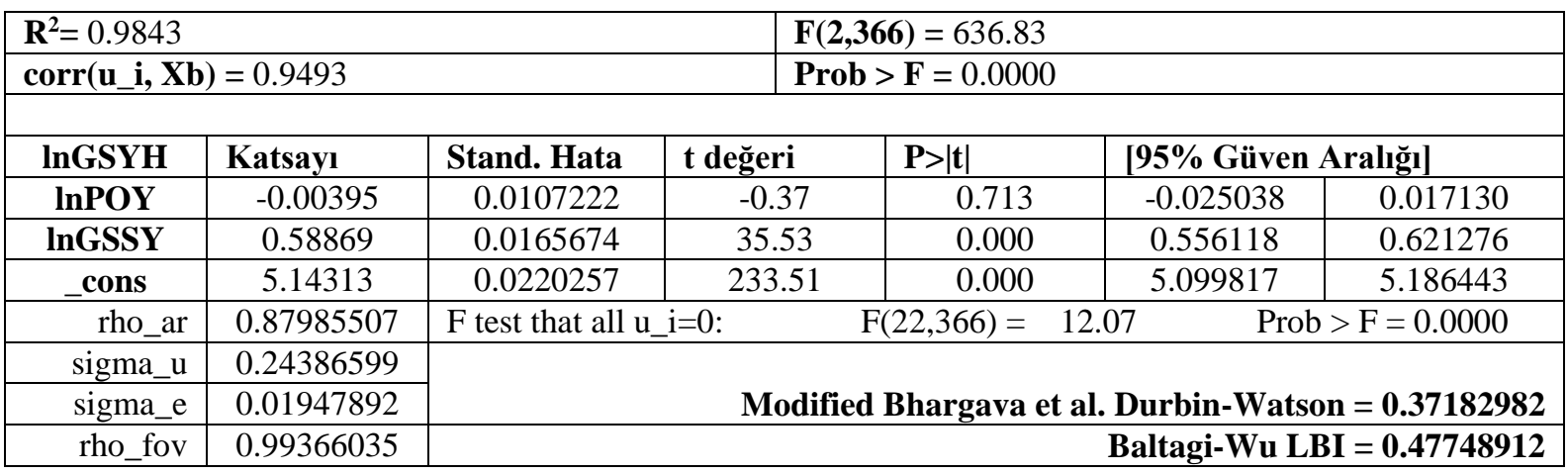

Tablo 6'da görüldüğü üzere modelde otokorelasyon sorununun olup olmadığını test etmek amaciyla uygulanan ilgili testler neticesinde test istatistiklerinin 2'den küçük olması sebebiyle modelde otokorelasyon olduğu sonucu elde edilmiştir.

Modelin değişen varyansa sahip olup olmadığının tespiti de ekonometrik analiz açısından önemlidir. Modele ilişkin değişen varyans sorununun varlığ 1 modifiye edilmiş Wald testi ile incelenmiştir. Tablo 7'de modifiye Wald testi ile gerçekleştirilmiş sabit varyans testi sonuçları yer almaktadır. Söz konusu test için kurulan hipotezler aşağıdaki gibidir:

$H_{0}$ : Değişen varyans yoktur.

$H_{1}$ : Değişen varyans vardır. 
Tablo 7. Sabit Varyans Testi Sonucu

\begin{tabular}{|r|l|}
\hline $\mathrm{H} 0: \operatorname{sigma}(\mathrm{i})^{\wedge} 2=\operatorname{sigma}^{\wedge} 2$ for all $\mathrm{i}$ \\
\hline chi2 (23) & 2866.28 \\
\hline Prob>chi2 & 0.0000 \\
\hline
\end{tabular}

Tablo 7'de sabit etkili regresyon modelinde grupsal heteroskedastisite için modifiye Wald testi incelendiğinde olasılık değerinin anlamlı olduğu, bu durumda da değişen varyans yoktur şeklinde kurulan $H_{0}$ hipotezinin reddedilip, değişen varyansın olduğunu ileri süren $H_{1}$ hipotezinin kabul edildiği görülmektedir.

Böylece bu çalışmada incelenen modelde yatay kesit bağımlılı̆̆ının, otokorelasyonun ve değişen varyansın mevcut olduğu tespiti neticesinde bu üç duruma uygun dirençli tahminciler veren Driscoll-Kraay tahmincisi kullanılmıştır. Tablo 8'de Driscoll-Kraay testi sonuçları yer almaktadır.

Tablo 8. Driscoll-Kraay Testi Sonucu

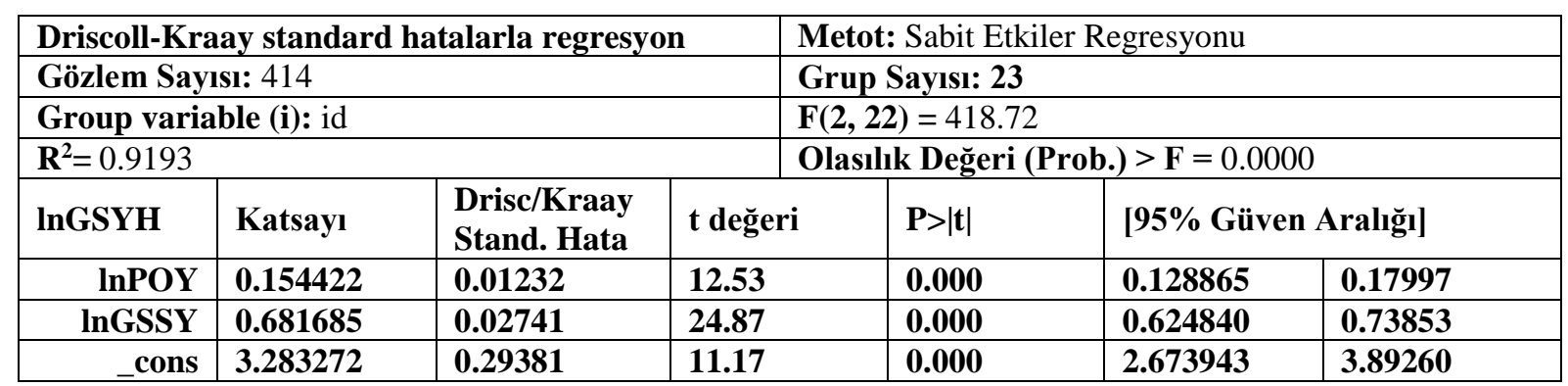

Tablo 8'de yer alan tahmin sonuçları incelendiğinde ve 23 OECD ülkesinde portföy yatırımları ile ekonomik büyüme arasındaki ilişkiyi incelemek amacıyla oluşturulan modelde uygulanan Driscoll-Kraay testi sonuçları değerlendirildiğinde portföy yatırımlarında meydana gelen \% $\%$ 'lik bir artışın GSYH üzerinde \%0,15 dolayında bir artışa neden olduğu görülmektedir. Ayrıca modele dahil edilen gayrisafi sabit sermaye yatırımlarının da aynı durumda GSYH'de \%0,68 oranında artışa neden olduğu sonucuna ulaşılmaktadır. Bu durumda ilgili test neticesinde elde edilen bulgular doğrultusunda çalışmada yer alan modelin nihai hali aşağıdaki gibi olacaktır:

$\ln G S Y H=3,28+0,15 \ln P O Y+0,68 \ln G S S Y$

Portföy yatırımlarının büyümeyi pozitif yönde etkilediği neticesi ile birlikte değişkenler arasında uzun dönemli ilişkinin olup olmadığı yani portföy yatırımlarının GSYH üzerindeki etkisinin uzun dönemde de gerçekleşip gerçekleşmediği politika yapıcıları için önemlidir. Panel veri setinde yer alan değişkenler arasındaki uzun dönemli ilişkinin tespit edilebilmesi panel eşbütünleşme analizleri ile gerçekleştirilmektedir. Birim kök testleri sonucunda elde edilen bulgular uygulanacak olan eşbütünleşme türünün belirlenmesinde oldukça önemlidir. Ayrıca serilerde yatay kesit bağımlılığının olması da uygulanacak testin belirlenmesinde büyük önem arz etmektedir. Bu durumda bu çalışmada Westerlund (2007) tarafindan geliştirilen, grup istatistikleri ve panel istatistikleri olarak iki kısımda ele alınan ve serilerin birinci farklarda durağan olduğunu varsayan Westerlund Bootstrap Panel Eşbütünleşme testi uygulanmıştır. Test için oluşturulan model aşağıdaki gibidir:

$$
\begin{aligned}
\Delta y_{i t}=\delta_{i} d_{t}+\lambda_{i} x_{i t-1}+\sum_{j=1}^{P_{i}} \alpha_{i j} \Delta y_{i t-j}+\sum_{j=0}^{P_{i}} \lambda_{i j} \Delta x_{i t-j}+e_{t} \\
y_{i t-1}=\delta_{i} d_{t}+\lambda_{i} x_{i t-1}+\sum_{j=1}^{P_{i}} \alpha_{i j} \Delta y_{i t-j}+\sum_{j=0}^{P_{i}} \lambda_{i j} \Delta x_{i t-j}+\varepsilon_{t}
\end{aligned}
$$

Bir sonraki aşamada panelin tamamı için hata düzeltme katsayısıyla bu katsayının standart hatası hesaplanmaktadır: 


$$
\begin{aligned}
& \alpha_{i}=\left(\sum_{i=1}^{N} \sum_{t=2}^{T} \tilde{y}_{i t-1}^{2}\right)^{-1} \sum_{i=1}^{N} \sum_{t=2}^{T} \frac{1}{\alpha_{i}(1)} \tilde{y}_{i t-1} \Delta \tilde{y}_{i t} \\
& S E\left(\alpha_{\mathrm{I}}\right)=\left(\left(\hat{S}^{2}{ }_{N}\right) \sum_{i=1}^{N} \sum_{t=2}^{T} \tilde{y}_{i t-1}^{2}\right)^{-1 / 2}
\end{aligned}
$$

Üçüncü ve son aşamada ise panel eşbütünleşme istatistikleri hesaplanmaktadır. Söz konusu hesaplama denklemi aşağıdaki gibidir:

$$
\begin{aligned}
& P_{t}=\frac{\alpha}{\operatorname{se}(\alpha)} \sim N(0,1) \\
& P_{a}=T_{\alpha} \sim N(0,1)
\end{aligned}
$$

Üç aşamalı olarak hesaplanmış olan eşbütünleşme istatistiklerinin hipotezleri ise aşağıdaki gibi oluşturulmaktadır:

$H_{0}: \alpha_{i}=0$; yatay kesitlerin tamamı için eşbütünleşme yoktur.

$H_{1}: \alpha_{i}=\alpha<0$; yatay kesitlerin tamamı için eşbütünleşme vardır.

Westerlund (2007) tarafından geliştirilmiş olan eşbütünleşme testleri standart normal dağılım kritik değerleri ile karşılaştırılırken paneli oluşturan yatay kesitler arasında bağımlılık olmadığını varsaymaktadır. Ancak Westerlund (2007), yatay kesit bağımlılı̆ı olması durumunda, bu durumu dikkate almak amaciyla hesaplanmış olan eşbütünleşme istatistiklerinin Chang (2004) tarafından önerilen bootstrap kritik değerleri ile karşılaştırılması gerektiğini belirtmiştir (Nazlığlu, 2010: 96).

Tablo 9. Westerlund ECM Panel Eşbütünleşme Testi

\begin{tabular}{|ll|c|c|c|}
\hline & Test İstatistiği & $\begin{array}{c}\text { Asimptotik Olasılık } \\
\text { Değeri }\end{array}$ & $\begin{array}{c}\text { Bootstrap Olasılık } \\
\text { Değeri }\end{array}$ \\
\hline $\boldsymbol{g}_{\boldsymbol{\tau}}$ (Grup Ortalaması) & -5.564 & 0.000 & 0.272 \\
\hline $\boldsymbol{g}_{\boldsymbol{\alpha}}$ (Grup Ortalamas1) & 4.949 & 1.000 & 0.980 \\
\hline $\boldsymbol{p}_{\boldsymbol{\tau}}$ (Panel) & -3.192 & 0.001 & 0.417 \\
\hline $\boldsymbol{p}_{\boldsymbol{\alpha}}$ (Panel) & 2.411 & 0.992 & 0.900 \\
\hline
\end{tabular}

Bootstrap olasılık değerleri 1000 tekrarlı dağılımdan elde edilmiştir.

Gecikme ve öncül seviyeleri olarak 1 alınmıştır.

Tablo 9'da Panel Eşbütünleşme sonuçları yer almaktadır. Tabloda asimptotik ve bootstrap değerleri bulunmaktadır. Ancak bu çalışmada yatay kesit bağımlılığının tespit edilmesi sebebiyle panel istatistiklerinin bootstrap dağılımına göre elde edilen sonuçlar değerlendirilmiştir. $\mathrm{Bu}$ durumda değişkenler arasında eşbütünleşme ilişkisi olmadığını ifade eden $H_{0}$ hipotezinin kabul edildiği yani değişkenler arasında uzun dönemde ilişki olmadığı sonucu elde edilmiştir.

\section{SONUC}

Ödemeler bilançosu dengesinde sermaye hesabı altında bulunan portföy yatırımları, özellikle 1980'li yıllarda artan uluslararası sermaye hareketleri ile birlikte ülke ekonomileri için politika belirleyici olarak önem sıralamasında en başlarda yer almaya başlamıştır. Özellikle gelişmekte olan ülkelerde tasarruf açıklarını kapatmak için en kolay yollardan biri dış tasarrufların ülkelerine gelmesini sağlamak olmuştur. Bunun için en önemli iki konu yatırımcısına yüksek gelir sağlamak ve yatırımcının güvenini kazanmaktadır.

Politika yapıcılarının yani iktidarı elinde bulunduranların, uluslararası finans çevrelerinin güvenini kazanmak için istikrardan yana ortodoks politikalara ağırlık verdikleri görülmüştür. Ancak ekonomik büyümeyi sıcak para adı da verilen bu dolaylı sermaye yatırımları ile sürdürmenin mümkün olup olmadığ 2000 sonrasında meydana gelen finansal gelişmelerle kısmen kendini göstermiştir. Buna rağmen portföy yatırımları gündemdeki yerini korumaktadır. Bunun en önemli nedeni yine özellikle gelişmekte olan ülkelerin 
kısa dönemde dış açıklarını kapatmalarının ve ekonomik büyümelerini sürdürmelerinin en önemli gereksinimlerinden birisinin portföy yatırımları olduğu düşüncesinin devam etmesidir.

Yapılan bu çalışmada portföy yatırımları ile ekonomik büyüme arasındaki ilişki 23 OECD ülkesine ait 2001-2018 dönemi verileri ile analiz edilmiştir. Bulgulara göre öncelikle ülkelere ait verilerin yatay kesit bağımlılı̆̆ özelliği taşıdığı yani verilerin birbirinden etkilendiği tespit edilmiştir. Daha sonra yapılan testlerde verilerin durağan olup olmadıkları araştırılmış ve birinci dereceden farklarının durağan oldukları sonucuna ulaşılmıştır. Yapılan otokorelasyon ve değişen varyans testleri sonucunda uygun regresyon analizi seçilmiş ve veriler regrese edilmiştir. Buna göre portföy yatırımlarının ekonomik büyümeyi pozitif etkilediği sonucuna ulaşılmıştır. Veriler aynı düzeyde durağan olduklarından dolayı analizin sonunda eşbütünleşme testi de yapılmış ve bu analiz sonucuna göre portföy yatırımları ile büyüme arasında uzun dönemli ilişki bulunmadığı görülmüştür. Kısaca portföy yatırımlarının kısa dönemde büyümeyi pozitif etkilediği ancak uzun dönemde büyüme üzerinde etkisinin olmadığı sonucuna ulaşılmıştır. 


\section{KAYNAKÇA}

Aizenman, Joshua, Yothin Jinjarak and Donghyun Park (2011). "Capital Flows and Economic Growth In The Era Of Financial Integration And Crisis, 1990-2010”. NBER Working Paper Series. Working Paper No: 17502.

Albulescu, Claudiu Tiberiu (2015), "Do Foreign Direct And Portfolio Investments Affect Long-Term Economic Growth In Central And Eastern Europe?” Procedia Economics And Finance. 23, 507-512.

Baltagi, Badi (2001), "Econometric Analysis of Panel Data”, 2nd Ed., UK: John Wiley \& Sons Ltd.

Bekaert, Geert and Campbell R. Harvey (1998). "Capital Flows and The Behavior of Emerging Market Equity Returns". NBER Working Paper Series. Working Paper No:6669.

Benli, Muhammed (2019). "Yabancı Portföy Yatırımı-İktisadi Büyüme İlişkisi: Yönlendirilmiş Döngüsüz Graflar Analizi”. Erciyes Üniversitesi İktisadi ve İdari Bilimler Fakültesi Dergisi. Sayı: 53, 59-72.

Demir, Yusuf (2007). "Yabancı Sermaye Yatırımlarının Ekonomik Büyümeye Olan Etkisinin Türkiye Bağlamında Test Edilmesi”. Muhasebe ve Finansman Dergisi. Say1.34, 152-161.

Duasa, Jarita and Salina Kassim (2009). "Foreign Portfolio Investment And Economic Growth In Malaysia". The Pakistan Development Review. 48:2, 109-123.

Durham, J.Benson (2004). “Absorptive Capacity And The Effects Of Foreign Direct Investment And Equity Foreign Portfolio Investment On Economic Growth”. Europen Economic Review. Volume.48, Issue.2, 285-306.

Esen, Oğuz (1998), Finansal Küreselleşme Ortamında Gelişmekte Olan Ülkelere Yönelik Portföy Yatırımları, Ekonomik Yaklaşım, Cilt 9, Sayı 30, 59-70.

Gülmez (2015), “Türkiye’de Dış Finansman Kaynakları Ekonomik Büyüme İlişkisi: ARDL Sınır Testi Yaklaşımı”. Ekonomik ve Sosyal Araştırmalar Dergisi, Cilt:11, Y11:11, Sayı:2, 139-152.

Karaca, Coşkun ve Tezcan Abasız (2008). "Gelir ve Bölge Ayrımına Göre Uluslararası Sermaye Hareketlerinin Ekonomik Büyüme Üzerindeki Etkisi: Ampirik Bir Analiz”. Çukurova Üniversitesi İİBF Dergisi. Cilt:12, Sayı:1, 19-33.

Kula, Ferit (2003). Uluslararası Sermaye Hareketlerinin Etkinliği: Türkiye Üzerine Gözlemler”. C.Ü. İktisadi ve İdari Bilimler Dergisi. Cilt.4, Say1.2, 141-154.

Kuzucu, Serpil (2018). "Doğrudan Yabancı Yatırımlar ve Portföy Yatırımları Ekonomik Büyümeyi Teşvik Eder Mi? Gelişmekte Olan Ülkelerden Kanıtlar”. Journal of Economics, Finance and Accounting, Volume:5, Issue:4, 331 338.

McLean, Ben and Sona Shrestha (2002). "International Financial Liberalisation and Economic Growth". Economic Research Department Reserve Bank of Australia. Research Discussion Paper, 2002-03. 1-24.

Nazlığlu, Şaban (2010). "Makro İktisat Politikalarının Tarım Sektörü Üzerindeki Etkisi: Gelişmiş ve Gelişmekte Olan Ülkeler İçin Bir Karşılaştırma”, Yayımlanmamış Doktora Tezi, Erciyes Üniversitesi, Sosyal Bilimler Enstitüsü.

Pesaran, M.Hashem, Aman Ullah and Takashi Yamagata (2008). "A Bias-Adjusted LM Test Of Error Cross-Section İndependence", Econometrics Journal, Volume:11, 105-127.

Pesaran, M.Hashem (2004). "General Diagnostic Tests for Cross Section Dependence in Panels", IZA Discussion Paper Series, No:1240, 1-39.

Reisen, Helmut and Marcelo Soto (2001). "Which Types of Capital Inflows Foster Developing- Coutry Growth?”. International Finance. Volume.4, Issue.1, 1-14.

Singh, Ajit and Bruce A.Weisse (1998). "Emerging Stock Markets, Portfolio Capital Flows and Long Term Economic Growth: Micro and Macroeconomic Perspectives", World Development, Vol.26, Issue.4, 607-622.

Soto, Marcelo (2000), "Capital Flows and Growth in Developing Countries: Recent Empirical Evidence”. OECD Development Centre. Working Paper No: 160. 1-33.

Sugözü, İbrahim Halil ve Murat Çetinkaya (2011). “Küresel Finansal Kriz ve Borç Krizi”, Küresel Ekonomik ve Finansal Kriz Türkiye Ekseninde Sorunlar ve Çözüm Önerileri, Ed. Murat Çetinkaya, ss.237-271

Topuz, Seher Gülşah ve Taner Sekmen (2019), "Sermaye Akışı ve Ekonomik Büyüme İlişkisi: Asimetrik Etkiler”, Mehmet Akif Ersoy Üniversitesi İktisadi ve İdari Bilimler Fakültesi Dergisi. Cilt:6, Say1:1, 154-171.

Vergil, Hasan ve Coşkun Karaca (2010), "Gelişmekte Olan Ülkelere Yönelik Uluslararası Sermaye Hareketlerinin Ekonomik Büyüme Üzerindeki Etkisi: Panel Veri Analizi”. Ege Akademik Bakış. Cil:10, Sayı:4, 1207-1216.

Vita, Glauco De and Khine S. Kyaw (2009). "Growth Effects of FDI and Portfolio Investment Flows to Developing Countries: A Disaggregated Analysis by Income Levels". Applied Economic Letters. 16(3), 277-283.

Westerlund, Joakim, (2007). "Testing for Error Correction in Panel Data", Oxford Bulletin of Economics and Statistics, Say1: 69/6, s. 709-748.

Yılmaz, Pelin (2011), Türkiye’de Finansal Serbestleşme ve Fonksiyonel Gelir Dağılımı, Yüksek Lisans Tezi, İzmir. 